\title{
The 3 Directions: Situated Information Literacy
}

\author{
James T. Nichols
}

\begin{abstract}
In-depth case studies of the research experiences of university students gave rise to a conceptual framework for understanding the students' behaviors related to reading, writing, and thinking as well as information seeking, the fundamental components of information literacy. The 3 Directions refer to the students' movements toward (1) a product-Actions and Products Direction; (2) learning about their subject-Cognition Direction; and (3) participation in a scholarly or professional community-Participation Direction. Situated cognition offers a full explanation of the 3 Directions. This model is applied to the assessment of advanced-level information literacy in the disciplines and to the design of a basic level online tutorial.
\end{abstract}

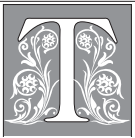

he complete scope of information literacy reaches beyond the information-seeking skills with which librarians are most familiar and reaches into domains in which librarians typically have no in-depth preparation. Consider what information literacy means for juniors and seniors in higher education: accomplishment of some kind in reading, writing, and critical thinking as well as information seeking, within particular disciplines of practice or scholarship. Most librarians would rightfully be reluctant to claim anything more than basic competence in critical thinking, for instance, in areas outside their own undergraduate studies.

One response, however unsatisfactory, is to focus on information seeking and closely related basic skills. This would result in putting a wall up around library and information use instruction and never venturing beyond that known and familiar territory. This leads to isolation of library activities from the related activities that give meaning and value to the use of the library.

A more productive and proactive response is to try to understand the information literacy experiences of our students and the situations in which they will need to seek and use information. Then we can think more creatively about how we can help our students and faculty and also offer to our students more of what we as information professionals know about the production, organization, and use of information. To promote this situated understanding, this article presents the 3 Directions Model, a framework that the author developed from an empirical base, and then reports on the author's experiences using the 3 Directions in program assessment and instructional design. The

James T. Nichols is Assistant Coordinator of Instruction and Distance Learning Librarian in the Penfield Library at the State University of New York at Oswego; e-mail: jim.nichols@oswego.edu. He gratefully acknowledges the support of his colleagues on the Instruction Team at Penfield Library, led by Karen Shockey. 
report on the research is abbreviated here to highlight the author's progression from data to theory to application within one article. $^{1}$

\section{Research Methodology}

The model presented here is first and foremost an attempt to understand student experiences and so is based on description and analysis of case studies of one junior and nine seniors at Indiana University Bloomington. Each student reported that they had a GPA of at least 3.0, and three of them were recruited through the honors program advisor in their department. The students were already taking at least one upper division course that required a library research paper. All but one student reported on their research for courses in art history, musicology, and American history. The students reported on their work on their papers through biweekly interviews, email journals, and other documentation (see Appendix A). The model presented here is rooted in these reports and was discovered through a descriptive analysis of the reports and a pattern-matching procedure. The descriptive phase of the study identified dozens of prominent actions, abilities, feelings, and other features of the information literacy experiences of these students. Analysis of the data included pattern-matching between the experiences of each student and each of four alternative models of information literacy behaviors:

(1) Kuhlthau's Information Search Process. This is taken as a linear pattern of movement through six stages of progressively focused learning with phases of uncertainty and low confidence followed by certainty and confidence. ${ }^{2}$

(2) A nonlinear model based on the recursive writing processes described by Hayes. This pattern emphasizes description of the process through categorization of actions or behaviors into four main categories: Social/Physical Environment (information retrieval, consultation, new text), Cognitive Pro- cesses (interpretation, reflection, text production), Motivation/Affect, and Knowledge (counterpart to Hayes's working memory and long-term memory). Any action can be called at any time, but some actions will predominate more than others at particular points in the overall process. ${ }^{3}$

(3) Dervin's Sense-Making Approach. The pattern here is based on identifying the situations faced by the students, the gaps that hinder movement toward goals, and the bridges used to overcome those gaps. ${ }^{4}$

(4) Scholarly communication as a community of practice entered through legitimate peripheral participation. Stoan first presented this approach to information literacy behaviors, and then Fister used it in a small study. For them the model marks a movement from formal means of communication available to outsiders toward informal means of communication available to the insiders in a disciplinary community. The author of the present study noted the consonance of this idea with the principles of situated cognition, as developed by Brown and Duguid, and Lave and Wenger, in which the novice to a field of practice serves a cognitive apprenticeship to gain entry to the core community of experts in that field. ${ }^{5}$

The research design itself was based in large part on Dervin's Sense-Making Approach, which stresses generalizing from the situations faced by the subjects rather than seeking to make generalizations about particular populations. ${ }^{6}$ The purpose of these case studies was to capture snapshots of the behaviors and actions of these students as they completed research paper assignments and then to identify patterns in these behaviors and actions. Consequently, the focus was on the individual experiences of the students situated in the context of their academic uses of information. Generalization of this model to other situations depends on the similarity of those other situations with the situations of these ten students. 


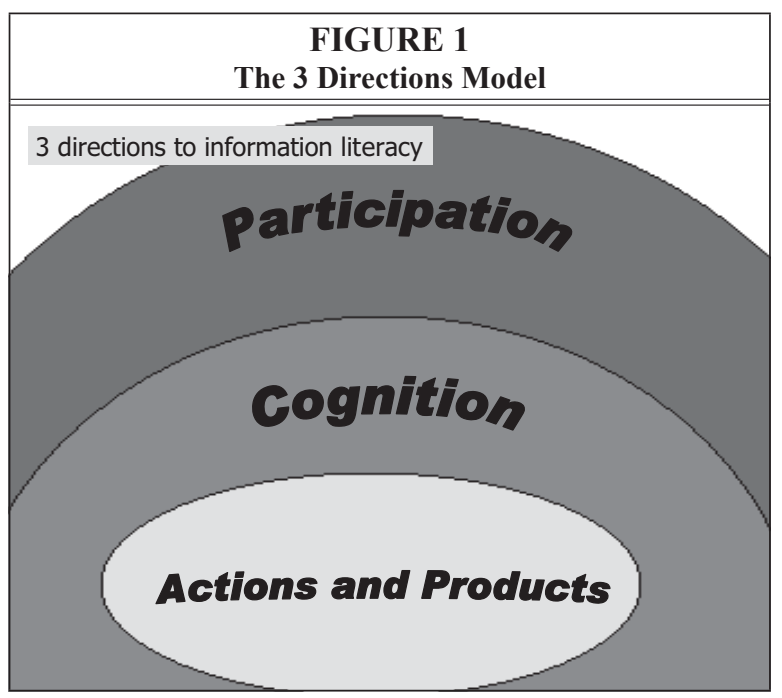

of academic research from the first notes about a topic to the completed paper or presentation (figure 2). The Cognition Direction moves from the point of knowing little to some point of knowing more about a particular subject matter and marks the different sorts of interpreting, questioning, and analyzing that constitute learning (figure 3). And the Participation Direction marks the progress of a student from a novice to becoming a member of a scholarly or professional

\section{The 3 Directions Model}

Examination of the ten cases through the perspectives of all four models brought to light three dimensions on which the students' experiences and activities may be positioned. In completing a research paper, these students moved along or made progress on each of these dimensions or directions (figure 1). The Actions and Products Direction traces the output or recording of the uses of information and includes all the tangible subproducts, precursors, and products discipline community (figure 4). Any one behavior could be placed on one, two, or all three directions depending on the specific situation.

The motif of students moving forward to goals is rooted in Dervin's Sense-Making, which assumes that such movement is a basic feature of human behavior. Interruptions in the movement are gaps for which humans construct bridges to continue progress toward goals. ${ }^{7}$ The Participation Direction comes directly from the scholarly communication model

\begin{tabular}{|c|c|}
\hline \multicolumn{2}{|c|}{$\begin{array}{c}\text { FIGURE } 2 \\
\text { The Actions and Products Direction }\end{array}$} \\
\hline $\begin{array}{l}\text { FROM: First statement of an information- } \\
\text { based task, assignment or problem } \\
\text { TO: Completed presentation of information } \\
\text { that fulfills the task } \\
\text { INCLUDES: Tangible expressions of } \\
\text { problems, questions, and needs as well as } \\
\text { solutions, answers, and gratifications; also, } \\
\text { retrieved information and tangible results of } \\
\text { interpreting and using that information. }\end{array}$ & $\begin{array}{l}\text { FOR THE CASE STUDY STUDENTS } \\
\text { (generally from start to finish): } \\
\checkmark \text { Assignment } \\
\checkmark \text { Topic statements } \\
\checkmark \text { Topic proposal } \\
\checkmark \text { Search statements } \\
\checkmark \text { Search results } \\
\checkmark \text { Bibliography } \\
\checkmark \text { Books, articles and other sources } \\
\checkmark \text { Notes } \\
\checkmark \text { Journal or log } \\
\checkmark \text { Outlines } \\
\checkmark \text { Synopsis } \\
\checkmark \text { Thesis statement } \\
\checkmark \text { Rough drafts } \\
\checkmark \text { Final draft }\end{array}$ \\
\hline
\end{tabular}




\begin{tabular}{|c|c|}
\hline \multicolumn{2}{|c|}{$\begin{array}{c}\text { FIGURE } 3 \\
\text { The Cognition Direction }\end{array}$} \\
\hline $\begin{array}{l}\text { FROM: Knowing less about a subject area } \\
\text { TO: Knowing more about that subject } \\
\text { INCLUDES: Uses of various types of } \\
\text { information such as context, background, } \\
\text { primary data, standard sources, and } \\
\text { argument; and the information uses } \\
\text { include interpretation, analysis, synthesis, } \\
\text { and formation of new knowledge. }\end{array}$ & $\begin{array}{l}\text { FOR UNIVERSITY UNDERGRADUATES: } \\
\text { Types of information } \\
\checkmark \text { Overview } \\
\checkmark \text { Standard sources } \\
\checkmark \text { Primary data } \\
\checkmark \text { Supporting information } \\
\checkmark \text { Citations } \\
\text { Uses of information } \\
\checkmark \text { "Going through sources" } \\
\checkmark \text { Scanning } \\
\checkmark \text { Interpretation } \\
\checkmark \text { Analysis } \\
\checkmark \text { Evaluation } \\
\checkmark \text { Problem solving } \\
\checkmark \text { Synthesis } \\
\checkmark \text { Comparison }\end{array}$ \\
\hline
\end{tabular}

and its underlying framework of cognition situated in legitimate peripheral participation in communities of practice. At the same time, an expanded understanding and application of the situated cognition framework offers powerful elaborations and explanations for all three directions.

In the following sections, I will define, characterize, and discuss each Direction; report any special analysis tasks on the case studies related to the Direction; point out notable relevance or departure with the models that are other than situated cognition; and analyze and elaborate on the Direction from the situated cognition framework. This treatment of each Direction will first speak from the data in the case studies, then view the data through the alternative models, and finally elaborate on the students' experiences in light of the body of research, principles, and

\begin{tabular}{|c|c|}
\hline \multicolumn{2}{|c|}{$\begin{array}{c}\text { FIGURE } 4 \\
\text { The Participation Direction }\end{array}$} \\
\hline $\begin{array}{l}\text { FROM: Novice in a community } \\
\text { TO: Fully participating member of a } \\
\text { community } \\
\text { INCLUDES: Shifting from formal } \\
\text { means of access to the discourse of a } \\
\text { community to informal means; learning } \\
\text { the conventions of a community such as } \\
\text { the vocabulary, genres, interpretive and } \\
\text { analytical strategies, and values. }\end{array}$ & $\begin{array}{ll}\text { FOR UNIVERSITY UNDERGRADUATES: } \\
\checkmark & \text { Local library catalog } \\
\checkmark & \text { Multidisciplinary bibliographic databases } \\
& \text { and indexes } \\
\checkmark & \text { Specialized dictionaries and encyclopedias } \\
\checkmark & \text { Field specific bibliographic databases and } \\
& \text { indexes } \\
\checkmark & \text { Scholarly books and articles } \\
\checkmark & \text { Tracing citations found in books and } \\
& \text { articles } \\
\checkmark & \text { Modeling current work on existing articles } \\
\checkmark & \text { Standard citation style for field } \\
\checkmark & \text { Discussing work with fellow students } \\
\checkmark & \text { Exploring ideas with faculty, in person or } \\
\checkmark & \text { by e-mail } \\
\checkmark & \text { Sources recommended by faculty }\end{array}$ \\
\hline
\end{tabular}


theory in situated cognition and legitimate peripheral participation in communities of practice.

\section{Actions and Products Direction}

From the interviews:

[One way computer searches are helpful] is you get the same things popping up over and over and so when you look at bibliographies and stuff you see the same names cropping up over and over so you start to see that it is a finite body of material that you are working with as far as a particular topic.

As I kept learning more stuff I kept looking off in other directions to learn more stuff about the new stuff, which kind of took a long time. That sounds like the research part that you should do before you write a paper but it's been my experience that's not the way it works. You don't do research and then write a paper, I mean you can do most of the research first but you start writing the paper and you realize that there is something that you don't know and you need to figure it out or you realize that there is a relationship between things in your paper that you didn't realize before and you somehow have to stick them together.

Probably the most obvious dimension is the movement from the point of receiving an assignment to the point of finishing the paper or other presentation. These tangible expressions of mental and physical behaviors look like the outputs of skills to many of us, which skills can be observed, objectively described, and then taught to students. More than isolated skills, however, the students presented expressions of problems, questions, and needs as well as solutions, answers, and gratifications. We also have information retrieved from both searches and sources and the tangible results of each student interpreting and using that information. Moreover, each expression is subject first to reading and interpretation; then to learning and other mental operations; and finally to new expression, which is also to be read and transformed into yet another expression in turn. Each product is the result of cognitive action and leads to new actions. So each student's movement from assignment to final draft may have been one big loop or cycle, but they reported myriad smaller loops from one expression to the next.

The analysis of the case studies specifically focused on the order and time frames of these behaviors in an attempt to test the relative validity of the linear stage model as opposed to the recursive model. An operational logic appeared to rule, since one does not have the capacity to search for a relevant source until one has settled on a topic; nor to select and read a source until one has done a search or found a bibliography and also obtained a copy; nor to make notes and plan a paper until one has read something; and so on. But these students engaged in a lot of recursions, too (see figure 5). So these actions and products cannot be taken as a list of cumulative steps. They are instead a catalog of the processes and procedures that the students called into action as needs and capacities arose in their particular situations. These actions do not form the linear stages of Kuhlthau's Information Search Process (alternative model 1). They do form the nonlinear, recursive pattern seen in Haye's Writing Processes (alternative model 2), conditioned by the progressive nature of the overall tasks.

From the perspective of situated cognition, these actions and products are more productively thought of as conceptual tools rather than isolated skills. As tools, they are best understood and learned when used in the context of a broader practice, embedded in a community and culture devoted to that practice. ${ }^{8}$ Reading the results of a search, for instance, is a meaningless exercise in isolation, but an 




invaluable action when the results identify a prominent scholar who can become a key source for the investigation in hand.

The situated cognition literature also cautions against treating this catalog of actions and products as a list of explicit concepts to be taught and learned. Relatively stable and pervasive elements may be selected and abstracted from practice and explicated to serve as guideposts for students as they negotiate a path into a community of practice, but most elements are best left implicit or tacit, to be discovered, shared, and used when most needed. ${ }^{9}$

While these tangible actions and products represent specific cognitive activities, they remain focused on one coherent outcome, the final draft. This Direction or dimension opens easily to the less tangible and less focused behaviors of cognition and learning.

\section{Cognition Direction}

From the interviews:

So yeah, I don't know, what did I learn? Like I learned things about the subject matter certainly, I learned things about researching, I learned things about how I need to continue work on time management, that sort of thing.

I don't want to just throw something together. I want this to be a logical process to come to my conclusion. I really want to make this a good paper, something I wouldn't be afraid to publish.

The thing about the research paper is I feel like it's more like discussing a topic instead of proving a thesis. But I think the more I can push it towards resolving a question the more interesting it will be and the more it will have a direction.

The second direction is the movement from knowing little about a subject and progressing to learning and knowing more. This may be marked by the types of information that are being used, including context, background, primary data, standard sources, and argument. What was notable among these students was that they were aware that their spheres of 
information were neither flat nor heaps of undifferentiated bits of facts. They were actively aware of the different types of information and sources they needed to use and the variety of uses they had for the information.

These students did not just read and take notes of bits of information to be transmitted. A few of them referred to "going through sources" instead. These were all accomplished students and readers, and yet they worked hard at reading, doing a lot of rereading and recursive reading, and noting unfamiliar words to be looked up. And especially in planning and drafting their papers, they were articulate about using information to develop background knowledge or to do comparisons or problem solving. Other information uses included interpretation, analysis, synthesis, and formation of new knowledge. Building new knowledge was important to these students. They expressed distaste for merely reporting and a desire for engagement with their subject matter.

The analysis of the case studies in part examined the affective element in research for these students. They were repeatedly asked to report their feelings about their work. They did not express the kind of library anxiety found in firstyear university students by Mellon. ${ }^{10}$ All but one did find the large main library to be an uncomfortable place to work, but they did not talk about it as a confusing, frightening, or overwhelming place; they simply preferred the intimacy and familiarity of the branch libraries for their respective schools. They did report worries at times about whether they had picked a good topic or had found enough sources, but these worries did not hinder them in resolving those issues. A few of them reported serious stresses and anxieties about other parts of their lives, but not about their research projects. The students did experience times of uncertainty, but not in any particular pattern. One student even expressed uncertainty about her choice of topic when the paper was done and graded, wondering if she would not have written on something else entirely if she had been more aware of the topic earlier.

It was also difficult to tease out the boundary between affect and cognition when it came to uncertainty and dissonance, which are as much emotional as cognitive. It is best to remember that the Cognition Direction is not just an intellectual domain but also very much a holistically personal one, in which emotion and intellect mix and flow together in the building of knowledge.

In regard to learning and cognition, each of the four alternative models is constructivist in nature. That is, they all assume that the learner is not a passive receiver for the transmission of knowledge. Rather, the learner actively builds her own knowledge. This construction is not strictly personal; rather, it is founded on social interaction in important ways. First of all, construction often operates on information received from others, but it does so in an active and transformative manner. Second, construction relies on consultation, negotiation, and verification with others to fully interpret and establish the meaning of knowledge, relying on the fundamentally social conventions of language, genre, canon, and research methodology. Finally, an individual's construction adds to the body of knowledge shared by a community. These are admittedly sweeping generalizations, but it is important to note them here as basic assumptions underlying this author's understanding of the alternative models and the analysis of the cases. At the same time, explanation and defense of social constructivism is beyond the scope of this article.

Kuhlthau is an avowed constructivist and directly discusses how her work fits with the constructivist ideas of Bruner and Vygotsky. ${ }^{11}$ Dervin bases her SenseMaking approach on the capacity of humans to construct figurative bridges to close the gaps they experience, often with the help of others. ${ }^{12}$ Hayes finds 
reflection, reading, and interpretation of text to be fundamental to building the content and form of new texts that by nature address a social audience. ${ }^{13}$ Situated cognition theory grew out of research that placed learning in community settings at the center of attention to broaden the understanding of education beyond teachers' pouring content into the heads of students. ${ }^{14}$

The students in the present cases were eager to learn. They learned to be better researchers, readers, and writers; they learned more about their chosen subjects; and they learned more about scholarly practices in their respective fields.

\section{Participation Direction}

\section{From the interviews:}

That is the other thing about using journal articles is that the authors in that case are facing the same criteria that you are. You know, writing a paper in this amount of space in 15 pages and convince people that is really a good idea. There were a couple of articles where I said, "Hey, I like the way that they started this paper." So I would bracket that and use it as a structural model for what I want my paper to be like.

About reading a book-you have a sense that all these scholars have to defend their position. It's actually really interesting that you're reading along and they have to really defend why they are doing this.

\footnotetext{
Actually, almost every book I checked out made some reference to Bateson's work, which is really kind of neat. I was like, "Wow, this guy's hot shit," because I guess he did some really new anthropological methods and stuff like that and just had a fresh look on how to analyze this culture or do anthropology in general.
}

But it seemed like they all sort of quote each other. Like this one was written in 1990 and so she had used a lot of what Hartman had written. I think her book was 1984, early '80s. That was kind of neat because I was able to sort of understand Hartman's arguments a little bit better even just because she was quoted throughout.

I've also started to wonder if the books I've been reading ever make their way out of academia. They're printed by universities and written by people who are probably part of the faculty. And I find them in a university library. Does this stuff ever GO anywhere? Maybe it does, through people like me who read it in school and then take it out with me when I graduate.

Finally, a student moves along the dimension from status as a novice to the point of being a scholar in a discipline. This direction directly fits legitimate peripheral participation in communities of practice. In this paradigm the novice gains a place on the sidelines or periphery of the community. At first the novice is given less critical, marginal tasks (but nonetheless important to the practice) and allowed to observe and talk about the whole field of practice, including the more advanced and critical tasks at the core of the community. Over time, a wider range of tasks are given and mastered, and the best practices and tricks of the trade are absorbed. The student progressively attains the abilities needed to enter the core membership of the community. ${ }^{15}$

Since access to sources is the heart of information seeking and use, the analysis of the cases focused on and found shifts from formal means of access to the discourse of a community, in catalogs and databases, to informal means of access through bibliographies in sources and faculty recommendations. The students also reported actions that showed learning of the conventions of a scholarly 
community such as the vocabulary and genres, interpretive and analytical strategies used by scholars, and the recognition of key sources and seminal works. One student used his sources as models for his own writing. Another reflected on how one of his sources was clearly written for scholars in a particular field.

For upper division undergraduates, the target community of practice is an academic discipline, whether in a liberal arts or professional field. In the Participation Direction, we can see progressive development of abilities beyond basic skills. The connection to a community of practice also afforded a sense of authenticity to their work. They were often quite aware of themselves as learning to do what they could see that scholars do. This direction also provides a long view that opens connections to lifelong learning and certainly, in many of these cases, a connection to graduate school and career.

\section{Discussion of the 3 Directions as a Model}

These 3 Directions of Information Literacy serve as a composite model that can subsume the four alternative models and also describe how the information literacy behaviors relate to each other and how the behaviors constitute expertise in undergraduate scholarship. These dimensions can also serve to describe the context and the situation for information literacy behaviors in academic settings.

It is important to have an understanding of this context because a list of competencies or skills alone is not enough to capture the kind of information know-how that the students in this study exhibited. The competencies are not of equal value, and the value of any one competency will vary according to the context and situation. It is not enough to know how to do a keyword search in a library catalog, for example. Such a search will be an empty exercise unless the student does such a search when it is needed and when the student is ready with enough of a topic definition and enough background knowledge to make a usable search statement and to make judgments of the usefulness of the sources in the search results. Thus, both the Actions and Products and the Cognition Directions come into play. Also, effective use of a keyword catalog search can hinge on the degree of a student's familiarity with the vocabulary and discourse in a discipline, especially when it comes to using the search to identify materials that are appropriate to the field and to the level of the student's work. Thus, the Participation Direction is part of the picture.

The 3 Directions Model may also have predictive and prescriptive power. If a student's current situation can be positioned on the Directions, however imprecisely, it may be possible to predict what actions the student is likely to take next. If a student needs help, a librarian or instructor can shape the advice that is offered to the student by identifying the student's position in the 3 Directions and urging the student to take the actions that have been used by other students in similar situations and so are most likely to advance them along the dimensions.

\section{Directions, the ACRL Standards, and Undergraduate Learning Outcomes}

About the same time as this model was developed (2000-2003), the ACRL Standards were published (2000); ${ }^{16}$ and a few years after that (2006), the medium-sized comprehensive college where the author now works, State University of New York at Oswego, began to develop a requirement for infusion of information literacy from basic to advanced levels through all undergraduate programs. A colleague and the author were assigned the task of drawing up learning outcomes for information literacy on a year-byyear basis (figure 6). Our starting points included the 3 Directions, the Standards, and a model document from Philadelphia University. ${ }^{17}$

We determined that the top-level Standards were useful to us as general descriptions of the practices that are most 
important in information literacy. They also carried the weight of a national professional body. However, the elaboration of the standards into indicators and learning objectives seemed unwieldy to us and drifted into a scattered focus on isolated skills. Instead, we laid out the essential abilities for first-year students and then drafted a coherent description of the library and information research practice we would expect of our graduating scholars.

The principal task remaining was to lay out how students could move from the first-year to the graduation levels across the most prominent milestones of our programs here. Instead of marching through freshman, sophomore, junior, and senior years, we used the first-year experience, gateway-to-major course, intermediate level (marked by requirements for upperdivision multidisciplinary courses and writing-in-the-discipline courses), and capstone experience. This allowed us to avoid a mechanical and linear sequence of skills through presumed levels of difficulty and to encourage multiple reiterations of the research process, giving students a chance to rehearse and improve their scholarly practice and bring themselves closer and closer to the practices at the core of their major field as they progress toward their capstone experience (figure 6).

In the resulting matrix in figure 6 , each of the 3 Directions is a thread. The Actions and Products Direction can be seen in the rows of the first four Standards, moving from the initiation of an information need through the use of information for a purpose. The Cognition Direction is most evident in the row for Standard 3, especially as the student furthers his or her knowledge base and value system. And then the Participation Direction is the basis for the progression through the four levels or columns, beginning with the students learning to be college students and growing to be scholars and practitioners in their chosen fields. Additionally, the major discipline as a community of practice is the anchor for the Capstone outcomes. The student is expected to show a command of the vocabulary, genres, rhetoric, literature, bibliography, methods, and other conventions of the community of practice, at least to the level of being able to read and use the scholarly communication in an academic discipline.

The implementation and assessment of infusion at the advanced level is proceeding in a way consistent with the 3 Directions Model itself. Rather than planning and developing a list of topics to be covered, we are working with faculty in each department, as the insiders in the discipline, to state the Capstone level learning outcomes in a manner consistent with the practice in each field. These outcomes will be used by the classroom faculty to develop an assessment of student information literacy practice on a five-year cycle for each department. We then expect the results of the assessments to drive future improvements in the instructional programs as needed.

Our principles for the assessments themselves are also drawn from the 3 Directions Model. If the main focus of learning is on practice, then the main task of assessment is to observe instances of authentic practice. It then follows that the work of assessment is to have each of the students develop a portfolio documenting the processes and products involved in a project that is valued by the student and relevant to his or her particular community of practice. A rubric tailored to the program can then be applied to the documentation to measure the quality of the students' work in the context of their communities of practice. Since most of our programs require scholarly or professional projects in their Capstone requirements, those projects have become a natural focus for assessing information literacy at that level.

\section{Directions in Rebuilding a Basic Level Tutorial}

Addressing the needs of first-year students presents a major pitfall for instruc- 


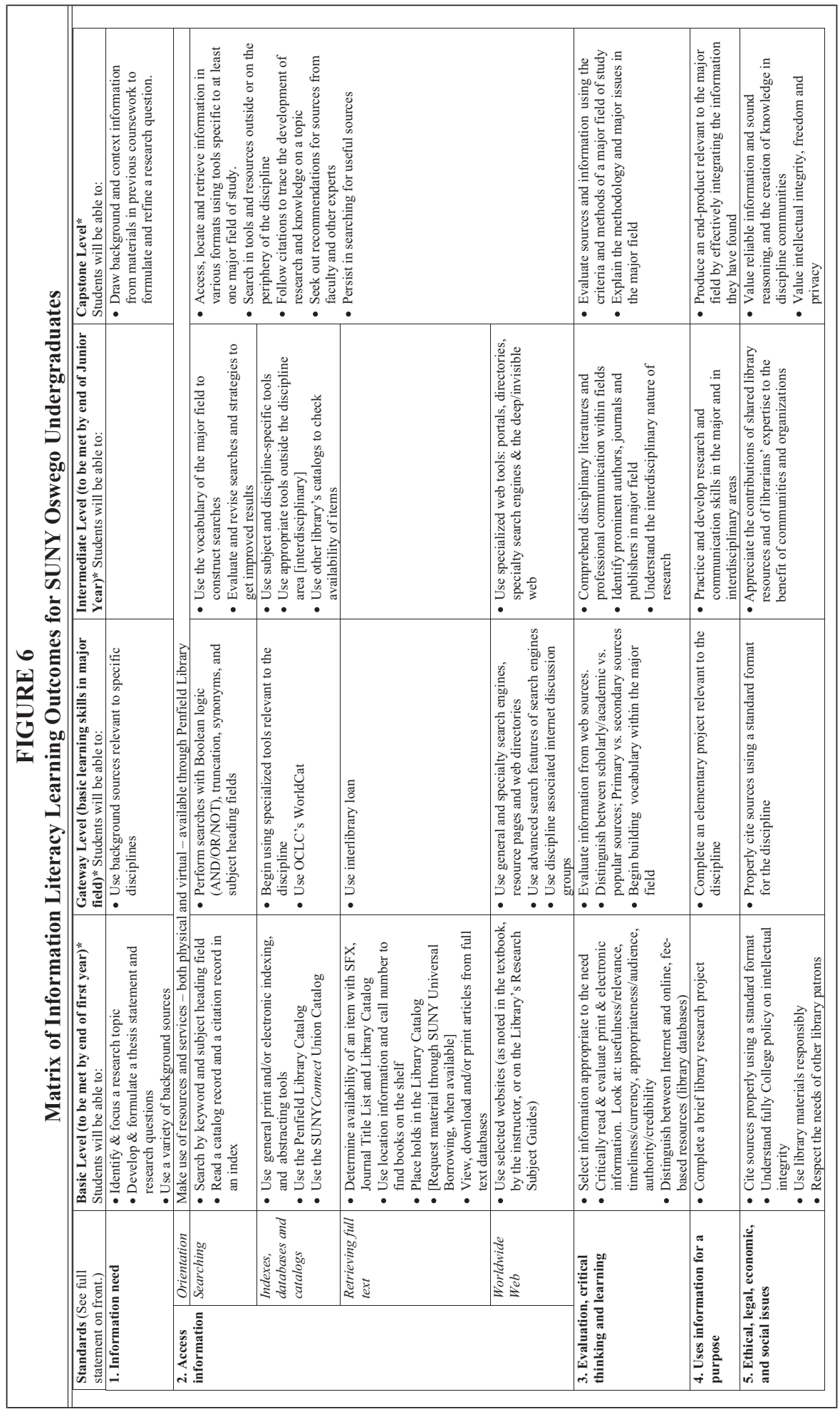


tion librarians when the situation is considered from the perspective of the 3 Directions. These new college students are still getting used to the overall college experience and have little immediate interest in the research activities and practices of their professors. Many have not even settled on a major. They can be a tough audience and there are a lot of them. At most colleges, they are at least a quarter of the undergraduate student body. They do seem to know from their high school experiences that they must learn to be college students as the first step to learning to be scholars. Their main task as novices in academic research is to make good use of the formal tools for access to sources - the very tools for which librarians are the experts. It is no wonder that we librarians immediately throw ourselves into the gratifying role of valued expert, reprising fifty-minute lecture/demonstrations in which we explicate the features and workings of a few search tools even though the tools will change within the year. And we persist in this kind of instruction even though in the long term we remain frustrated at how little the students seem to retain.

At SUNY Oswego, we have been using an online tutorial with an accompanying worksheet (intended to be used in conjunction with a class research assignment on a topic of the student's choosing) to meet the needs of our first-year students. We first mounted the tutorial in 2001 and have used a variety of assessment methods to identify ways to improve it, including a rubric applied to the worksheets on a selective basis and an initial pretest/posttest study. ${ }^{18}$

The tutorial authors have also participated in numerous workshops and professional development activities offered by the college's Center for Excellence in Learning and Teaching. In these activities we have learned to avoid lecturing and covering the tools and instead to rely on active learning; to elevate the learning beyond the collection of facts and isolated skills and toward reflection and critical consideration of sources and practices; to respect our students as people who have probably seen and used library catalogs and online searches and who expect college to be different from high school; and to make our presentations transparent to scholarly communities of practice: that is, to give the students a clear view of the connections between the librarians' formal tools and the practice of scholarship. ${ }^{19}$ As a result, when we undertook a complete redesign of the basic tutorial in 2006, we planned from the start to incorporate elements from the 3 Directions and situated cognition.

The material is organized on an interlinked, modular basis, allowing for use of any or all of the modules as best suits the needs of the students and instructors. This allows students to use or revisit the parts that address particular tools and practices on a conditioned basis, as we would expect them to in their progress on the Actions and Products Direction. The modular approach also allows for linking to modules for more advanced tools and techniques or to more specific work in the disciplines, addressing the Cognition and the Participation Directions.

We focused on showing the use of common types of tools and sources and giving students an immediate opportunity to try it for themselves. Explication is minimal and reserved for guiding concepts. We relied on exploration and discovery for the tacit elements, many of which will continue to change. So we labeled and pointed out the availability of assigned subject headings, for example, suggesting that they can afford more precise searches without ever belaboring the difference between those and free text search words. These approaches to instruction are consistent with the needs of students indicated in the Actions and Products and the Cognition Directions.

We took every opportunity to connect our instructional material and the work of first-year students to the practices and traditions of scholarly research and communication, to start them on their 
paths on the Participation Direction. In exploring a potential topic, we point out the names of experts and scholars in the background source. Whether searching for books, articles, or Web sites, we point out the availability of scholarly sources in that particular type of material. And in the treatment of evaluation and citation of sources, we tie the source in hand to possible communities of practice in regard to audience, methodology, credentials, and references to other sources in the field.

\section{Contributions of the 3 Directions Model}

Even today, almost twenty years after the ALA Presidential Committee on Information Literacy and twenty-five years after Kuhlthau's first work with the Information Search Process with high school students, ${ }^{20}$ the 3 Directions Model appears to be the only model of college-level information literacy behaviors rooted in an empirical base - the reported experiences of upper-division university students. Other empirical studies of information literacy among university students aim to evaluate the learning and teaching of skills or to test limited hypotheses and thus fall short of shaping a model or conceptual framework for the information literacy actions of students. Most attempts at building models for college students remain theoretical and do not draw on any data from the experiences of students.

Christine Bruce in 1997 and Annemaree Lloyd in 2005 have each developed models of information literacy. Bruce interviewed librarians and instructors about their perceptions of information literacy and drew conclusions on what students should think about information literacy, but she does not interview students about their perceptions or analyze reports or observations of what students are able to do. ${ }^{21}$ Lloyd studied information uses among a group of firefighters finding a vital community of practice and evidence of legitimate peripheral participation as the means of entry to that community. She suggests the relevance of her model of information literacy landscapes to the information uses of university students, and what she describes is consistent with the 3 Directions, but she has not done the empirical work to confirm her model among students. ${ }^{22}$ The reliance of the 3 Directions on the reported experiences of students places their information uses and behaviors into the context and culture of academic research and affords us a view of the connections of information literacy to students' educational programs and to scholarly communities of practice.

From a critical pedagogy perspective, Elmborg characterizes nearly all existing models of information literacy as process models that posit stages that students can be taught to move through to a completed research product. The alternative he offers is fundamentally a call for research such as reported here and a call for conceptualizing information literacy as practices situated in particular situations and communities as can be seen in the 3 Directions Model. In Elmborg's terms, the 3 Directions Model makes a theoretical contribution by moving information literacy education beyond the banking or sender-receiver model of teaching and learning. ${ }^{23}$ This Model brings information literacy learning onto new ground consistent with critical pedagogy, social constructivism, sociocultural approaches, and postmodernism.

Finally, the 3 Directions Model and the analysis it affords us can provide direction for improvements in information literacy education programs and learning. The better we can see the big ideas and guiding concepts in the context of use, the better we can focus the learning activities on things that will have a lasting impact and enable continuing learning.

\section{Further Research}

The next step in research on the 3 Directions is to develop and refine methodology for feasible monitoring of student experiences. If cases can be documented and analyzed more easily, then information can be brought together to refine the 
Model and explore how stable or helpful the model might be across students' situations in diverse settings and across generations, especially in the face of continuing technological advances. Perhaps elements of the 3 Directions Model can provide an anchor for us and our students as the digital world shifts around us.

A second area of further research would be to identify "good practice" for learning information literacy. Although the author has not made it a focus for this research, the author has seen in these case studies and in interviews with graduate students that students are able to recall how and when they learned information literacy behaviors. One simple question could be added to interviews: "How did you learn to do that?" In a related vein, program assessments such as those described above should be able to uncover some successes in the teaching and learning of information literacy, as well as to generate innovations in teaching undergraduates to do academic research.

And a further avenue for research is to explore the relationship of information literacy behaviors to student engagement and academic success. The National Survey of Student Engagement is rooted in the correlation of student engagement behaviors with indicators of retention and success. The ways in which information literacy activity may fit into the factors of student engagement has been explored in a collaboration between NSSE and the ACRL Instruction Section. ${ }^{24}$ Although the current surveys do not include any items specific to information seeking, the broadened and contextualized view from the 3 Directions makes it possible to relate several of the existing items directly to information literacy. A 3 Directions analysis of NSSE results could become a valuable adjunct to other means of assessing information literacy programs.

\section{Conclusion}

The most important task of an undergraduate student is to learn to be a member of a discipline community, to tap into the knowledge and practice embodied in that community. Her path will take her from somewhere outside the discipline to a place inside. Librarians, as noted in the introduction, are generally outside the discipline; but we have a practice and expertise of our own that helps us understand the work, especially the communication and publication practices, of the various disciplines in ways that are not accessible to those inside. And, conversely, course instructors are deep inside their discipline and know the core practice in ways that most librarians will never be able to access. The instructors and librarians are both engaged in facilitating the passage of the student-the librarians opening doors for her from the outside; the instructors, from the inside..$^{25}$ It remains the burden of the student, as in the cases examined in this study, to progress in the 3 Directions: becoming adept in a toolkit of Actions and Products; learning deeply and broadly and gaining a command of reading, writing, thinking, and inquiry to have some real power in Cognition; and to enter into full Participation in a community of practice. 


\title{
Appendix A - Typical Interview Questions
}

\author{
Can you give me a recap of what you have done on your research assignment?
}

[For each matter mentioned] Where and when did you do this? How did you go about it?

What, if anything, do you see as blocking your progress on your assignment, or presenting a hurdle to your progress? What has helped you in your work or in removing any blocks or hurdles?

What questions have you had in your mind in regard to your assignment or the subject of your research? What questions do you have in your mind now? What has helped you in getting answers to your questions?

\section{Notes}

1. Since the research and projects reported in this article extend through several years, I offer the following notes on the dates: Fall 1998-Interviewing and other data collection. 1999-Summer 2000-Transcription and analytical coding of the data, and descriptive analysis of each case. Summer 2000-Move to current employment. 2000-2003-Summary descriptive analysis of the cases, pattern matching, and initial development of the 3 Directions; also the development and testing of the first version of the online information literacy tutorial. 2004-2006-Development of the Matrix of Information Literacy Learning Outcomes, based on the 3 Directions, and the drafting of program-specific plans. 2006-2008-Rebuilding the information literacy tutorial based on the 3 Directions.

2. Carol Collier Kuhlthau, "Library Research Process Case Studies and Interventions with High School Seniors in Advanced Placement English Classes Using Kelly's Theory of Constructs" (Ed.D. diss., Rutgers, the State University of New Jersey, 1983); Carol Collier Kuhlthau, "Developing a Model of the Library Search Process: Cognitive and Affective Aspects.," RQ 28, no. 2 (Jan. 1, 1988): 232-42; Carol Collier Kuhlthau, Seeking Meaning: A Process Approach to Library and Information Services (Norwood, N.J.: Ablex Pub. Corp., 1993).

3. Linda Flower and John R. Hayes, "A Cognitive Process Theory of Writing," College Composition and Communication 32, no. 4 (Dec. 1981): 365-87; John R. Hayes, "A New Framework for Understanding Cognition and Affect in Writing," in The Science of Writing: Theories, Methods, Individual Differences, and Applications (Hillsdale, N.J.: Lawrence Erlbaum Associates, Inc, 1996), 1-27.

4. Brenda Dervin, "From the Mind's Eye of the User: The Sense-Making Qualitative-Quantitative Methodology," in Qualitative Research in Information Management (Englewood, Colo.: Libraries Unlimited, 1992), 61-84.

5. S.K. Stoan, "Research and Information Retrieval among Academic Researchers: Implications for Library Instruction," Library Trends 39, no. 3 (Winter 1991): 238-58; Barbara Fister, "The Research Processes of Undergraduate Students," Journal of Academic Librarianship 18, no. 3 (July 1992): 163-69; John Seely Brown, Allan Collins, and Paul Duguid, "Situated Cognition and the Culture of Learning," Educational Researcher 18, no. 1 (Jan. 1, 1989): 32-42; John Seely Brown and Paul Duguid, "Stolen Knowledge," Educational Technology 33, no. 3 (Jan. 1, 1993): 10-15; Jean Lave and Etienne Wenger, Situated Learning: Legitimate Peripheral Participation, (New York: Cambridge University Press, 1991). Concurrent with this study and independently, Annemaree Lloyd discovered the relevance of Legitimate Peripheral Participation in Communities of Practice to the information uses of firefighters. Lloyd, "No Man (or Woman) Is an Island: Information Literacy, Affordances and Communities of Practice," Australian Library Journal 54, no. 3 (2005), available online at www.alia.org.au/publishing/alj/54.3/full.text/lloyd.html [Accessed 5 February 2009]. Annemaree Lloyd, "Information Literacy Landscapes: An Emerging Picture," Journal of Documentation 62, no. 5 (2006): 570-83.

6. Dervin, "From the Mind's Eye of the User."

7. Dervin, "From the Mind's Eye of the User."

8. Brown, Collins, and Duguid, "Situated Cognition and the Culture of Learning."

9. Ibid.; Brown and Duguid, "Stolen Knowledge."

10. Constance A. Mellon, "Library Anxiety: A Grounded Theory and Its Development," College 


\section{College \& Research Libraries}

and Research Libraries 47, no. 2 (Jan. 1, 1986): 160.

11. Kuhlthau, Seeking Meaning.

12. Dervin, "From the Mind's Eye of the User."

13. Hayes, "A New Framework for Understanding Cognition and Affect in Writing."

14. Lave and Wenger, Situated Learning.

15. Ibid.

16. Association of College \& Research Libraries, "Information Literacy Competency Standards for Higher Education," 2000.

17. "Information Literacy Framework for Philadelphia University: Information Literacy in the Curriculum at Philadelphia University," The Information Literacy Project @Philadelphia University (Mar. 2006). Available online at www.philau.edu/infolit/InfolitFrameworkbulleted.htm. [Accessed 5 February 2009].

18. James Nichols, Barbara Shaffer, and Karen Shockey, "Changing the Face of Instruction: Is Online or In-class More Effective?," College and Research Libraries 64, no. 5 (2003): 378-88.

19. Lave and Wenger, Situated Learning; W.C. Bosch et al., "Beyond Lip-Service: An Operational Definition of "Learning-Centered" College," Innovative Higher Education 33, no. 2 (2008), doi:10.1007/s10755-008-9072-1.

20. ALA Presidential Committee, "ALA Presidential Committee on Information Literacy: Final Report" (1989), available online at www.ala.org/ala/acrl/acrlpubs/whitepapers / presidential.cfm\#age [Accessed 5 February 2009]; Kuhlthau, "Library Research Process Case Studies and Interventions."

21. Christine Susan Bruce, "The Relational Approach: A New Model for Information Literacy," New Review of Information \& Library Research 3 (Jan. 1997): 1-23.

22. Lloyd, "No Man (or Woman) Is an Island"; Lloyd, "Information Literacy Landscapes."

23. James Elmborg, "Critical Information Literacy: Implications for Instructional Practice," The Journal of Academic Librarianship 32, no. 2 (Mar. 2006): 192-99.

24. Bonnie Gratch-Lindauer, "Information Literacy-Related Student Behaviors: Results from the NSSE Items," College and Research Libraries News 68, no. 7 (Aug. 2007): 432-36, 441. Available online at www.ala.org/ala/acrl/acrlpubs/crlnews/backissues2007/julyaugust07/ infolitstudent.cfm. [Accessed 5 February 2009].

25. James Nichols, e-mail communication, Apr. 27, 2007.

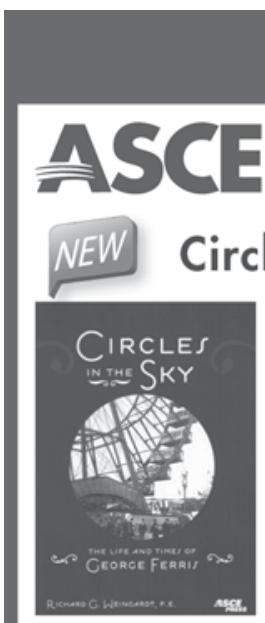

pubs.asce.org

年

PUBLICATIONS

structure of its time to rival the Eiffel Tower. It is, at the same time, the story of the Ferris Clan, one of the nation's oldest and most fascinating families. Circles in the Sky will enchant anyone interested in engineering marvels, history, and the Ferris Wheel, which reminds us that America was built by dreamers and innovators such as George W. G. Ferris, Jr.

2009 ASCE Press I Softcover I ISBN 978-0-7844-1010-3 Stock \#41010 I 162 pp. I List \$35.00 I ASCE Member \$26.25

\section{Women in Engineering}

Margaret E. Layne, P.E., Editor

These two anthologies of essays, articles, lectures, and reports span a century of historical and social analysis, and detail the triumphs and challenges women have faced in engineering, while bringing to vivid life their contribu-

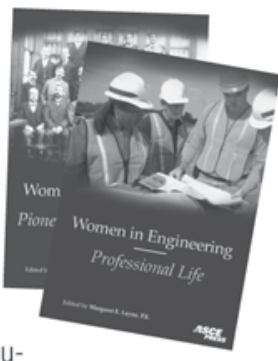
tions to engineering, and to history.

Pioneers and Trailblazers

2009 ASCE Press I Softcover I ISBN 978-0-7844-0980-0 I Stock \#40980 | 256 pp. List $\$ 39.00$ I ASCE Member $\$ 29.25$

Professional Life

2009 ASCE Press I Softcover ISBN 978-0-7844-0991-6 | Stock \#40991 | 264 pp. List $\$ 35.00$ I ASCE Member $\$ 26.25$

\section{How to Order}

Web: pubs.asce.org

Ph: 1-800-548-2723 / 1-703-295-6300 